\title{
NARRATIVAS DO ESPAÇO HABITADO: SENSIBILIDADES NO ESTUDO DOS PRÉDIOS ESCOLARES DE PORTO ALEGRE/RS (1940/1980)
}

\author{
Lucas Costa Grimaldi ${ }^{1}$ \\ Dóris Bittencourt Almeida ${ }^{2}$
}

\section{RESUMO}

O presente estudo investiga espaços escolares a partir das narrativas de estudantes de Porto Alegre/RS, no período de 1940 a 1980. Analisaram-se as edificações das seguintes escolas: Colégio Marista Rosário, Colégio Anchieta, Colégio Americano e Colégio Farroupilha. A pesquisa cartografou sensibilidades sobre o espaço vivido pelos estudantes durante a escolarização. Neste estudo, privilegiou-se o exame dos periódicos escolares, fotografias e plantas das edificações, encontrados nas escolas. Além disso, também examinamos o conteúdo discursivo de entrevistas realizadas, tendo como metodologia a História Oral. Para tanto, construíram-se quatro categorias de análise: "O Antigo e o Novo: relações entre os estudantes e os prédios das escolas"; "Entre a vigilância e a diversão: o espaço escolar como elemento curricular"; "A escola como casa: sensações de pertencimento" e, por fim, "A arquitetura escolar e a sensação de liberdade". Considera-se que os espaços habitados na escola adquirem um lugar de destaque na hora de narrar suas memórias. Estas memórias do espaço habitado trazem evidências para compreender

${ }^{1}$ Universidade Federal do Rio Grande do Sul (UFRGS), Porto Alegre/RS, Brasil.

2 Universidade Federal do Rio Grande do Sul (UFRGS), Porto Alegre/RS, Brasil. 
a arquitetura escolar como um elemento central durante a escolarização.

Palavras-chave: história da educação, arquitetura escolar, sensibilidades.

\title{
NARRATIVAS DEL ESPACIO HABITADO: SENSIBILIDADES EN EL ESTUDIO DE LOS EDIFICIOS ESCOLARES EN PORTO ALEGRE / RS (1940/1980)
}

\section{RESUMEN}

El presente estudio investiga los espacios escolares basados en las narrativas de estudiantes de Porto Alegre / RS, de 1940 a 1980. Se analizaron los edificios de las siguientes escuelas: Colégio Marista Rosário, Colégio Anchieta, Colégio Americano y Colégio Farroupilha. La investigación mapeó las sensibilidades sobre el espacio vivido por los estudiantes durante la escuela. En este estudio, el examen de los diarios escolares, fotografías y planos de construcción encontrados en las escuelas fue privilegiado. Además, también examinamos el contenido discursivo de las entrevistas realizadas, utilizando la Historia Oral como metodología. Con este fin, se construyeron cuatro categorías de análisis: "Lo viejo y lo nuevo: relaciones entre estudiantes y edificios escolares"; "Entre vigilancia y diversión: el espacio escolar como elemento curricular"; "La escuela como hogar: sentimientos de pertenencia" y, finalmente, "La arquitectura escolar y el sentimiento de libertad". Se considera que los espacios habitados en la escuela adquieren un lugar destacado al narrar sus recuerdos. Estos recuerdos del espacio habitado aportan evidencia para entender la arquitectura escolar como un elemento central durante la escolarización.

Palabras clave: historia de la educación, arquitectura escolar, sensibilidades.

\section{NARRATIVES OF THE INHABITED SPACE: SENSITIVITIES IN THE STUDY OF SCHOOL BUILDINGS IN PORTO ALEGRE / RS (1940/1980)}

\begin{abstract}
The present study investigates school spaces based on the narratives of students from Porto Alegre / RS, from 1940 to 1980 . The buildings of the following schools were analyzed: Colégio Marista Rosário, Colégio Anchieta, Colégio Americano and Colégio Farroupilha. The research mapped sensitivities about the space lived by students during schooling. In this study, the examination of school journals, photographs and building plans found in schools was privileged. In addition, we also examine the discursive content of interviews conducted, using Oral History as a methodology. To this end, four categories of analysis were built: "The Old and the New: Relationships between Students and School Buildings"; "Between surveillance and fun: the school space as a curricular element"; "The school as home: feelings of belonging" and, finally, "The school architecture and the feeling of freedom". It is considered that the spaces inhabited in the school acquire a prominent place when narrating their memories. These memories of inhabited space bring evidence to understand school architecture as a central element during schooling.
\end{abstract}

Keywords: history of education, school architecture, sensitivities. 


\section{RÉCITS DE L'ESPACE HABITÉ: SENSIBILITÉS DANS \\ L'ÉTUDE DES BÂTIMENTS SCOLAIRES DE PORTO \\ ALEGRE / RS (1940/1980)}

\section{RÉSUMÉ}

Cette étude explore les espaces scolaires à partir des récits des élèves de Porto Alegre / RS, de 1940 à 1980. Les bâtiments des écoles suivantes ont été analysés: Colégio Marista Rosário, Colégio Anchieta, Colégio Americano et Colégio Farroupilha. La recherche a cartographié les sensibilités de l'espace vécu par les élèves pendant la scolarité. Dans cette étude, l'examen des journaux scolaires, des photographies et des plans de construction trouvés dans les écoles a été privilégié. De plus, nous examinons également le contenu discursif des entretiens menés, en utilisant l'Histoire Orale comme méthodologie. À cette fin, quatre catégories d'analyse ont été construites: «L'ancien et le nouveau: relations entre les élèves et les bâtiments scolaires»; «Entre surveillance et divertissement: l'espace scolaire comme élément de programme»; «L'école comme chez soi: sentiment d'appartenance» et enfin "L'architecture de l'école et le sentiment de liberté». On considère que les espaces habités dans l'école acquièrent une place de choix lors de la narration de leurs souvenirs. Ces souvenirs d'espace habité apportent la preuve de la compréhension de l'architecture scolaire comme élément central de la scolarité.

Mots-clés: histoire de l'éducation, architecture scolaire, sensibilités. 


\section{INTRODUÇÃO}

Das paredes pintadas de verde (um verde grosso, antiquado) pendiam quadros, empastados de enfeites, das primeiras turmas de bacharelandos do Ginásio. Aqueles todos decerto já eram advogados, médicos, talvez deputados... O fazendeiro não se podia furtar à ideia agradável de que um dia o retrato do filho estaria também num quadro assim, exposto à admiração de outros eu viriam recémchegando...[...]Apesar dessas escapadas da imaginação, a espera naquela sala penumbrenta, silenciosa, fatigava. Aos poucos ia se gastando a boa disposição que os animava ao penetrarem no edifício. $\mathrm{O}$ guri entrevia na taciturnidade do casarão, uns indícios sombrios da prisão que o aguardava (MARTINS, 1942, p. 36).

Iniciamos o presente texto com um excerto do livro "O menino vai ao colégio", publicado em 1942, no qual o narrador tece algumas considerações sobre o espaço escolar que acabou de conhecer. Destacam-se as palavras de Cyro Martins que dizem respeito à autobiografia do autor, nas quais relata memórias do período que se escolarizou. Estas palavras atuam como inspiração e também como primeiras reflexões sobre o que será discutido neste estudo. Dos fragmentos que selecionamos para iniciar o presente texto, emergem memórias permeadas de percepções e sensações que têm por foco a experiência no espaço escolar e nos permitem indagar, principalmente, de que formas os estudantes habitaram o espaço escolar e como foram afetados por ele.

Nesse sentido, é preciso pensar a concepção material das escolas como produto de seu tempo, e também como intersecção de discursos arquitetônicos, pedagógicos e históricos. Viñao Frago (1998, p.26) exemplifica que esta materialidade atua como "um programa, uma espécie de discurso que institui na sua materialidade um sistema de valores, como os de ordem, disciplina e vigilância, marcos para a aprendizagem sensorial e motora e toda uma semiologia que cobre diferentes símbolos estéticos, culturais [...]”. 
O estudo da materialidade escolar, além da percepção destes discursos apontados por Viñao Frago (1998), possibilita a compreensão dos modelos de construções escolares. Sendo assim, Zevi (1990, p.27) considera este espaço como o substantivo, isto é, o protagonista da arquitetura. E para tanto discorre que "a história da arquitetura é, essencialmente, a história das concepções espaciais" e, além disso, a história da produção de espaços.

"O espaço é um lugar praticado" (CERTEAU, 2008, p.120). Para o autor, lugar e espaço são conceitos com significados distintos, o primeiro diz respeito ao que foi demarcado, a sua materialidade intransponível, o segundo corresponde à maneira pela qual esse lugar foi praticado, representado ou rememorado.

Todo esse esforço em pensar a espacialidade escolar torna-se possível, entre outras coisas, pelo fato desses espaços não serem neutros, são "construções culturais que expressam e refletem para além de sua materialidade, determinados discursos" (ESCOLANO, 2001, p.26). Também se pode pensar nesses espaços que atuam como o "suporte físico da educação" (DÓREA, 2013, p. 162), o lugar, ou os lugares onde a prática pedagógica cotidiana toma forma, e, como tal, "estão dotados de significados e transmitem uma importante quantidade de estímulos, conteúdos e valores" (ESCOLANO, 2001, p.27).

Nesse sentido, da arquitetura escolar como transmissora de estímulos, é interessante pensar os modos de objetivação, a partir dos espaços escolares, isto é, de que maneira fomos transformados em sujeitos, a partir de um discurso espacial disciplinar. Tendo como referencial teórico-metodológico a perspectiva das relações de poder foucaultianas, entendemos que, de forma alguma somos sujeitos passivos desses discursos espaciais, afinal sempre existe resistência. Também, é interessante pensar nos modos de subjetivação que escapam a esse discurso dominante, a partir, principalmente, da noção de tática de Michel de Certeau (2008), que vem do cotidiano. Para o autor (CERTEAU, 2008), as táticas seriam as resistências do "corpo a corpo", "o golpe preciso", uma hábil 
utilização do tempo, "movimento dentro do campo de ação do inimigo" frente às relações de poder instituídas.

Algumas perguntas ressoam, a partir desses referenciais: Como se produzem sujeitos no embate com a norma/disciplina no sentido espacial/arquitetônico? Como nos assujeitamos a determinados discursos espaciais da escola? Quais sensibilidades podem ser produzidas nos embates com esses discursos e em relações de poder? Cabe deixar claro, que o assujeitarse diz respeito a uma perspectiva foucaultiana a "se tornar sujeito de ...", não passivamente, pois, considerando essa concepção teórica, onde há poder há resistência3.

Trazendo elementos para pensar essas questões, podemos dizer que a institucionalização da escola, na Modernidade, demandou prédios e espaços próprios para a prática educativa (FOUCAULT, 2014; URIA e VARELA, 1992; BOTO, 2017). Esses espaços escolares tinham funções disciplinares e de enclausuramento do estudante, sendo a vigilância e a punição elementos importantes para o estabelecimento das práticas pedagógicas. Para Foucault, o estudo desses espaços institucionalizados, para além de sua estrutura, possibilita novas abordagens, seria preciso fazer uma "história dos espaços" que seria ao mesmo tempo uma "história dos poderes" que estudasse desde as grandes estratégias da geopolítica até as pequenas táticas do habitat, da arquitetura institucional, da sala de aula ou da organização hospitalar, passando pelas implantações econômico-políticas (FOUCAULT, 2017, p. 61).

A partir dessa proposição foucaultiana, de pensar uma história dos poderes e dos espaços e de relacionar com os modos de objetivação, houve a necessidade teórico-metodológica de transitar na intersecção de campos de saber: história da educação, história da arquitetura escolar e história das sensibilidades. Pois, como diz o autor: "É preciso antes multiplicar os caminhos e as possibilidades de idas e vindas" (FOUCAULT, 2008, p. 304).

3 Sobre a questão do poder no pensamento de Michel Foucault, ver Foucault (2014); (2017) e (1968). 
Essas “idas e vindas” filiam-se às perspectivas teórico-metodológicas da História Cultural. E por isso, podemos pensar na perspectiva material escolar como um discurso que produz sensibilidades, a partir das experiências/habitações nesse espaço, tendo na memória o eixo principal de análise, pois, como afirma Ricoeur (2007, p. 45): "nada temos de melhor que a memória para garantir que algo ocorreu antes de formarmos sua lembrança”.

Portanto, o objetivo deste estudo é investigar memórias de prédios e espaços escolares, problematizando a experiência sensível evocada por estudantes de quatro instituições de ensino de Porto Alegre/RS, no período de 1940 a 1980. O corpus documental privilegiado são narrativas de discentes inventariadas nos acervos das escolas, tais como redações e periódicos escolares, que foram estudados a partir da metodologia da análise documental histórica. Também trazemos algumas entrevistas produzidas com a metodologia de História Oral4. Para além, são importantes para a pesquisa, os documentos imagéticos, como fotografias, mapas da cidade e plantas arquitetônicas 5 .

Após a delimitação temática e metodológica, selecionamos para análise os prédios e espaços das seguintes instituições escolares: Colégio Americano, fundado pelos Metodistas, em 1885; Colégio Anchieta, fundado pelos Jesuítas, em 1890; Colégio Farroupilha, fundado pela Associação Beneficente e

44 Neste estudo, tivemos como foco a análise do material encontrado no arquivo das instituições, tais como periódicos escolares e redações. Sobre as oito narrativas orais produzidas no âmbito da pesquisa, ver Grimaldi e Almeida (2020).

5 As fontes foram inventariadas nos museus e arquivos dessas instituições. Do Colégio Americano inventariamos: fotos do Museu do Americano, exemplares do Jornal Escolar "O Crisol" do período de 1926 -1962.Correspondências e Históricos da mudança da escola, 2 Álbuns Memorialísticos - 1955 e 1998, plantas arquitetônicas das edificações da escola e produzimos duas entrevistas com as ex-alunas Nelly e Elaine. Do colégio Anchieta inventariamos: livro da Campanha de arrecadação de fundos para o novo prédio; plantas arquitetônicas do Prédio da Rua Duque de Caxias; livro "O menino vai ao Colégio" - Cyro Martins - Narrativa autobiográfica; 10 Plantas do Novo Anchieta; livros Memorialísticos: Memória Anchietana e Folheto Comemorativo aos 118 anos e produzimos duas entrevistas com os ex-alunos Fernando e Marcos. No Colégio Farroupilha amealhamos: plantas arquitetônicas do prédio chamado "Velho Casarão; reportagens do Jornal - O Clarim;Redações de estudantes do Curso Científico; fotografias das sedes; correspondências e relatórios A.B.E; relatórios de Inspeção Ginasial; material da Comissão de Propaganda do Novo Farroupilha e produzimos duas entrevistas com os ex-alunos Martin e Ana Luisa. Do Colégio Rosário: edições do anuário Echos do Ginásio Rosário;fotos de espaços escolares retiradas do Echos; albuns fotográficos comemorativos; plantas arquitetônicas e produzimos duas entrevistas com os ex-alunos José Eduardo e Sérgio. 
Educacional $^{6}$, em 1886 e o Colégio Rosário, fundado pelos Maristas, em 1904.

Neste sentido, a presente escrita divide-se em três momentos: primeiramente, analisamos a história das sensibilidades e suas intersecções com a história da educação, em seguida, a relação entre arquitetura escolar e sensibilidades e por último intitulado: "Cartografias do sensível” comentamos algumas categorias de análise das entrevistas, a partir do conceito de sensibilidades.

\section{HISTÓRIA CULTURAL, SENSIBILIDADES E HISTÓRIA DA EDUCAÇÃO}

Há 13 anos, no capítulo inicial do livro "História e História Cultural”, (2005), a historiadora Sandra Pesavento comenta que as pesquisas em História Cultural correspondem a "80\% da produção historiográfica nacional” (p. 7). Dez anos antes, na Europa, Antonio Viñao Frago comentava que "raro es el mês em el que no aparece, com está rubrica, algun nuevo livro o artículo o no se convoca algún seminário, congreso o simpósio” (1995, p.63).

Sobre isso, os dois autores consideram um sucesso de adesão às pesquisas ancoradas na referida corrente, tanto no âmbito da história quanto no da história da educação. Houve a ampliação do olhar para o horizonte da cultura, não de uma história da cultura, mas de múltiplas: escolares, urbanas, visuais, materiais. Há, como diz Pesavento, "renovação das correntes da história e dos campos de pesquisa, multiplicando o universo temático e os objetos, bem como a utilização de uma multiplicidade de novas fontes” (2005, p. 69). Este movimento só foi possível a partir de uma modificação nos paradigmas da ciência que originaram uma "redefinição nas questões culturais nas Ciências Humanas e na História" (CUNHA, 1999, p. 40).

Vinao Frago (1995) exemplifica que esse novo universo de

\footnotetext{
${ }^{6}$ A Associação Beneficente e Educacional, mantenedora do Colégio Farroupilha, foi criada em 1858 para dar auxilio à comunidade alemã de Porto Alegre. Sobre, ver Jacques (2013).
} 
possibilidades temáticas não se fez a partir de uma perspectiva fragmentada, mas sim, conectada e integrada. Em 1995, o autor acrescenta algumas possibilidades, "La historia de La cultura material y la del mundo de las emociones, lós sentimientos y lo imaginário, así como El de las representaciones e imágenes mentales” (VIÑAO FRAGO, 1995, p. 64).

Para os dois autores, há uma virada na escrita da história, uma atualização na perspectiva multidisciplinar que já vinha sendo utilizada desde a primeira geração dos Annales ${ }^{1}$, mas que previa uma perspectiva que cruzasse os conhecimentos e não hierarquizasse as ciências. Houve um abandono no caráter quantitativo e totalizante da primeira geração dos Annales. Cunha (1999) chama de uma "falência de modelos explicativos, das grandes teorias explicadoras do real social” (1999, p.40). Por isso, a emergência de novas percepções acerca do sujeito e da história, "redefinindo objetos, conteúdos e métodos, bem como fronteiras disciplinares que se atenuam na busca de uma inter, multi e transdisciplinaridade" (CUNHA, 1999, p. 40).

Seguindo nessa análise da história cultural, Pesavento (2005) afirma que a História Cultural corresponde a uma corrente historiográfica que combina três conceitos que se complementam. As noções de imaginário, de representação e de sensibilidades compõem o cerne dos estudos no campo, sendo terreno fértil para as mais diversas análises e objetos, como os citados por Viñao Frago no excerto anterior.

Outra particularidade dessa corrente é a da "compreensão da História como uma narrativa que constrói uma representação sobre o passado" (PESAVENTO, 2005, p. 69), seja através dos discursos, imagens e diferentes produções do passado. Novos objetos e novas abordagens de antigos objetos são o mote da análise feita através da História Cultural, percebendo que a cultura permeia todos os extratos e instituições da sociedade, devemos "pensar a história cultural como uma certa forma de abordagem do real histórico e, ao mesmo tempo, encarar a dimensão ou perspectiva cultural como alguma coisa que está presente na economia, na política e na sociedade como um todo” 
(FALCON, 2006, p. 334).

Dessa forma, o presente textp emergiu, tendo como mote o inventário das memórias discentes, em periódicos e redações escolares e em narrativas produzidas pela metodologia de História Oral, bem como pela análise de fontes iconográficas. Esse conjunto de documentos foi analisado pelas lentes do conceito de sensibilidade. Esta lente só pode ser pensada a partir de mudanças paradigmáticas e da intersecção dos conceitos de representação e imaginário, fundamentais para a história cultural, onde se desenvolve a noção de sensibilidade. Para Cunha, isso se deve a uma transição, que abalou as antigas certezas e que, transformou a ciência no trato com o subjetivo. Essa mudança, abre-se espaço para a percepção de dimensões do homem que escapam à lógica formal, mas que são também indispensáveis - a emoção e a sensibilidade: alegrias, medos, angústias, incertezas, temores, euforias que, ao transcenderem o individual constituem-se em forças mobilizadoras do social (CUNHA, 1999, p. 40).

Após essa redefinição da percepção e dos paradigmas, houve uma valorização das questões relacionadas aos sentimentos, às reações, aos sujeitos, enfim. O conceito da sensibilidade possui uma historicidade que o estabelece "à margem da história das ideias, das representações, dos corpos ou das imagens" (GRUZINSKI, 2007, p. 7).

Antes, ignorado pelos historiadores², emergiu uma mudança no olhar, principalmente, a partir da publicação do livro “O outono da Idade Média”, em 1919, por Johann Huizinga, onde o autor discorre sobre alguns sentimentos comuns dos homens do medievo. Para Regina Schöpke (2015), o autor trouxe "cor" ao homem da idade média, ressaltando suas particularidades.

Huizinga não era um historiador da cultura, porém captou aspectos indispensáveis para a História Cultural. Essa cor ressaltada no "Outono da Idade Média”, também é reiterada por Serge Gruzinski, em seu prefácio no livro "Sensibilidades na história: memórias singulares e identidades sociais" (2007), onde o pesquisador discute sobre a capacidade da História das Sensibilidades 
em "rejuvenescer a história do político, fustigar a história das imagens trazendo para o primeiro plano os mecanismos da recepção e da absorção, agita a história das artes, explorando a percepção dos estilos [...]” (GRUZINSKI, 2007, p.8). A sensibilidade age como uma espécie de verniz, na hora de ser empregado em antigas temáticas de pesquisa, a partir da subjetividade que é intrínseca à sensibilidade.

Para Marcos Taborda (2018) outros autores também trabalharam com a temática dos sentidos e sensibilidades: Carlo Ginzburg, Edward Thompson, Norbert Elias, Gilberto Freyre. “Todos esses trabalhos, muito já clássicos. Embora não tenham sido pensados para qualquer tipo de história da educação, nos mostram formas de definição, mobilização, estabilização e transformação das sensibilidades" (TABORDA, 2018, p.119).

Com o emprego desse conceito, tudo se pauta na questão da percepção e do indivíduo. Esta "aventura da individualidade" (PESAVENTO, 2007, p.10) também possui a capacidade de “capturar as razões e os sentimentos que qualificam a realidade, que expressam os sentidos que os homens em cada momento da história, foram capazes de dar a si próprios e ao mundo" (PESAVENTO, 2007, p. 10). O conhecimento sensível opera como uma forma de reconhecimento e tradução da realidade que brota não do racional ou das construções mentais mais elaboradas, mas dos sentidos, que vêm do intimo de cada individuo" (PESAVENTO, 2005). Por serem sociais e históricas , percebese que as sensibilidades, também carregam uma historicidade e condições para sua emergência.

A sensação de medo ao adentrar, pela primeira vez, o portão de uma escola, a ansiedade do primeiro dia de aula, a sensação claustrofóbica que alguns prédios escolares provocam, as lembranças mais queridas dos espaços em que se escolarizou: é disso que trata a presente pesquisa, afinada à história das sensibilidades, do indivíduo e suas sensações, reações. Assim, as sensibilidades podem ser tratadas como uma representação do passado, e que chega ao historiador através de um discurso, de múltiplas linguagens. 
Esses discursos sobre o passado devem ser tratados a partir de questionamentos: Quem fala? Por que fala? E de onde fala? De que lugar fala? Pra quem fala? Essas são questões norteadoras para se construir qualquer análise, seja em documentos escritos, imagéticos ou produzidos em depoimentos orais e também para entender as condições de emergência desses discursos. São essas indagações que desnaturalizam o discurso, principalmente, pelo fato de que, a produção do discurso é ao mesmo tempo controlada, selecionada, organizada e redistribuída por certo número de procedimentos que têm por função conjurar seus poderes e perigos, dominar seu acontecimento aleatório, esquivar sua pesada e temível materialidade. (FOUCAULT, 1999, p .9)

Importa pensar que o discurso, qualquer que seja ele, não é natural, há uma ordem que o precede, segundo Pesavento esta seria uma das propostas da História Cultural, isto é, compreender "a realidade do passado por meio das suas representações, tentando chegar àquelas formas discursivas e imagéticas, pelas quais os homens expressaram a si próprios e o mundo" (PESAVENTO, 2005, p. 42).

O discurso do sensível é produto de um tempo, construção histórica, e assim, como todo fragmento da história, pode ser problematizado. Não é apenas algo individual, por ser uma construção histórica e cultural, não é algo intransferível, como afirma Nadia Weber (2005), as pessoas podem compartilhar das mesmas sensações, e estas podem até ser formadores de uma identidade em comum. Valendo do pensamento de Corbin, certamente, eles não sentem a mesma coisa, mas compartilham de alguns "recobrimentos, de sedimentações, de inércias” (CORBIN, 2005, p.17) importantes para a História Cultural. A fim de perceber como pessoas e também grupos sentem, Corbin (2005, p. 18) atenta que devem ser levados em conta alguns critérios como "o sexo, a idade, a categoria social, o local geográfico, a tradição, ou a cultura que se recebeu". Tais atravessamentos tornam esta análise algo complexo e que necessita levar em conta que somos, principalmente interseccionados por diversos discursos e que ocupamos uma infinidade de lugares/posições de 
sujeito.

A partir dessa análise, o conceito de sensibilidade e sua aplicação na sistematização dos documentos têm por finalidade captar os sentidos e a percepção dos estudantes sobre espaços e prédios que os moldavam, vigiavam, puniam e incutiam ideais3. Além de perceber como os indivíduos sentiam os espaços, também se pretendeu "identificar a utilização dos sentidos que permitiu construir imagens do outro, dar forma ao imaginário social" (CORBIN, 2005, p. 19), pensando, principalmente, nos grupos de estudantes. Pesavento (2007, p.21) reafirma que o estudo das sensibilidades "não é sentir da mesma forma, é tentar explicar como poderia ter sido a experiência sensível de um outro tempo pelos rastros que deixou”. Não há uma facilidade em perceber estes rastros, o historiador que trabalhar com a sensibilidade precisa aguçar o olhar para captar essas falas da individualidade.

\section{ARQUITETURA ESCOLAR E AS SENSIBILIDADES}

Considera-se a arquitetura e o espaço escolar como discursos e também espaços não neutros, "construções culturais que expressam e refletem para além de sua materialidade, determinados discursos" (ESCOLANO, 2001, p.26). Essa é uma maneira recente de pensar a arquitetura escolar, por muitos anos houve um predomínio das análises de arquitetos e historiadores da arte, pois os edifícios escolares eram analisados, principalmente, a partir de suas características estruturais e de seus elementos decorativos. Como se houvesse uma essência a ser analisada, para Guatteli (2012, p.19) havia uma forma de teleologia histórica ao se falar das competências e atributos do espaço em arquitetura, sem os considerar como algo produzido culturalmente.

Superando essa discussão, a história da arquitetura escolar ${ }^{1}$ do século XXI vem ao encontro de uma perspectiva multidisciplinar. Arquitetos, historiadores e pedagogos passam a estudar esta materialidade da escola e enfocam diversas particularidades, tais como, a questão dos projetos dos 
edifícios, o ambiente como um elemento curricular, mas não exclusivamente, o espaço como responsável por questões de punição e vigilância, o mobiliário das escolas, o prédio na trama da cidade entre outros.

A historiadora da arquitetura escolar Anne-Marie Chatelet (2011) afirma, a partir de seu balanço historiográfico sobre a produção no campo², "parece que não há uma única maneira, ou espera-se, de escrever a história dos edifícios escolares e que em torno desse objeto comum surgiu uma variedade de abordagens que criou sua diversidade e sua riqueza" (CHATELET, 2011, p. 219).

Dessa multiplicidade de análises, me atenho as que consideram o espaço como transmissor de estímulos, significados e discursos. O historiador da educação, Agustín Escolano na introdução do capítulo "Arquitetura como Programa. Espaço-Escola e currículo3”, se vale de um breve relato,

Quando já havia completado os cinquenta anos de idade, o protagonista da narrativa visitou a escola que havia frequentado sua infância, entre os seis e os dez anos de idade. [...]Além das antigas estruturas, o observador pôde notar que o edifício ainda mostrava alguns elementos funcionais e decorativos da época em que havia frequentado a escola. [...]As salas de aula lhe pareceram sem dúvida menores; os corredores, mais estreitos; a escadaria, pela qual se subia ao andar superior; onde estavam as salas de aula das meninas, com menos degraus; o pátio do recreio, muito reduzido. [...]Mas a memória não lhe era infiel: o espaço que contemplava era, ainda que menor, o mesmo cenário de sua infância, e os lugares que observava correspondiam aos seus primeiros esquemas perceptivos (grifo meu). A escola havia sido, para ele, depois da sua casa e de alguns limites próximos a ela, uma experiência decisiva na aprendizagem das primeiras estruturas espaciais e na formação de seu próprio esquema corporal. [...]O relato mostra a profunda impressão que as primeiras experiências do espaço organizado - o espaço escolar vivido - deixaram no observador. [...]. (ESCOLANO,2001, p. 22-24)

O excerto acima trata a questão da interação entre a materialidade e os sujeitos que a frequentam. Com o termo "experiência vivida", passamos a analisar dentro do prédio escolar, a sensibilidade dos estudantes. Para o autor, 
pode-se considerar que os espaços deixam uma "profunda impressão" (2001, p.23), ou marca nas memórias dos sujeitos.

Pode-se ainda acrescentar ao relato outras situações vivenciadas pelos estudantes, e que também produzem marcas profundas, como trocas de prédios e espaços, construções e inaugurações de espaços novos, e principalmente, das construções que propiciaram novas atividades e práticas pedagógicas. Além disso, a experiência relatada por Escolano (2001) abre a possibilidade de pensar outros aspectos simbólicos da arquitetura que fogem da descrição funcional arquitetônica ou decorativa.

Ainda sobre as experiências sensíveis, Bencostta, ao entrevistar a pesquisadora francesa Anne-Marie Chatelet, interroga,

\footnotetext{
mas permita-me saber sua opinião acerca da importância de investigações que trabalham com o espaço experimentado, percebido e utilizado. Apesar de esta ser uma discussão, aparentemente, de maior atenção entre os sociólogos da educação, como nós, historiadores da arquitetura escolar, podemos tratar de uma arquitetura espacial enquanto experiência do vivido" (CHATELET, 2011, p. 215).
}

A pesquisadora responde que essa questão se une "às relações entre espaço e educação" (2011), e que, por utilizar as regulamentações do Ministério da Instrução Pública Francês em sua tese de doutorado, não foi possível se aproximar das questões do sensível. Segundo ela, "teria sido necessário recorrer às memórias de professores ou alunos, o que é um gênero raro"4. A autora continua, "os regulamentos são preservados, os testemunhos são raros", principalmente, por tratar de escolas do século XIX, na França. Chatelet (2011) assinala uma das dificuldades na análise das questões do sensível nos prédios escolares, porém, a autora não considera em sua fala, a possibilidade de captar esses traços em Jornais Escolares e em Fotografias, sem limitar o tipo de fonte.

Para aproximar essa análise, a presente pesquisa, no contexto de Porto Alegre, muitos espaços eram alugados e adaptados para fins de constituírem 
escolas, desde o século XIX. Devido à impossibilidade de captar as representações sensíveis dos estudantes no século XIX, delimitamos a pesquisa para um recorte temporal de 1920 a 1980, período que possibilita a realização de entrevistas com a metodologia de História Oral, e a análise do material iconográfico e da imprensa escolar.

Os prédios escolares, em geral, obtiveram configurações distintas, conforme o período histórico, ordens religiosas e discursos que deveriam transmitir. A elaboração de projetos-tipo, de modelos de espaços para a escola republicana e de uma espacialidade caracterizada pela vigilância, punição e por questões de higiene são alguns dos aspectos que o complexo campo da História da Arquitetura Escolar se propõe.

Para além das possibilidades analíticas que o campo engloba, há a necessidade de discorrer sobre algumas questões metodológicas. Antonio Viñao e Marcus Bencostta (2009), em balanço historiográfico sobre as publicações referentes à espaço e arquitetura escolar no Brasil e na Espanha, apresentam seis questões que devem ser levadas em conta durante o estudo da temática.

A primeira seria "a necessidade de distinguir entre o espaço desejado ou proposto [...] e o prescrito legalmente, o realmente construído ou utilizado [...] o espaço, experimentando, percebido e vivido" (VIÑAO FRAGO; BENCOSTTA, 2009, p. 34). Na segunda questão, é colocada a necessidade de perceber a configuração do espaço, as funções e atividades de cada local e de que forma eles se relacionam com os outros espaços de uma mesma instituição. $O$ terceiro aspecto leva em conta a relação do espaço em torno da "dialética entre o interno e o externo, o aberto e o fechado (sua porosidade, acessibilidade ou comunicabilidade em relação ao exterior) [...]”.

O quarto e o quinto aspectos tratam da necessidade de pensar o espaço escolar e o tempo escolar e da percepção do espaço como representações onde os atores agem em um cenário específico. No sexto aspecto, os autores enfatizam a necessidade de comparar distintos espaços escolares. Para Viñao e Bencostta (2009, p.35), "somente a partir da comparação é possível chegar a 
construir ordenações e classificações explicativas de modelos ou tipologias espaciais".

Nos valemos destas questões e partimos da comparação do espaço de quatro instituições escolares (Colégio Anchieta, Colégio Americano, Colégio Rosário e Colégio Farroupilha) e suas relações com o espaço urbano de Porto Alegre para compreender de que formas os estudantes evocavam e evocam sensibilidades daqueles espaços construídos. Prédio e espaços não são apenas materialidade, são cenário por onde os atores exercem a prática educativa e também constituem como fomentadores de uma experiência subjetiva.

\section{CARTOGRAFIAS DO SENSÍVEL: UM PANORAMA SOBRE AS CATEGORIAS ANALÍTICAS A PARTIR DO CONCEITO DE SENSIBILIDADE}

As categorias de análise apresentadas anteriormente partem de uma perspectiva genealógica foucaultiana, que procura entender as condições de possibilidade/emergência de algum determinado acontecimento, tendo como foco não homogeneizar a história, privilegiar suas descontinuidades em detrimento das regularidades. A partir do que propôs Foucault sobre a finalidade da genealogia,

marcar a singularidade dos acontecimentos longe de toda finalidade monótona; espreitá-los lá onde menos se os esperava e naquilo que é tido como não possuindo história - os sentimentos, o amor, a consciência, os instintos; apreender seu retorno não para traçar a curva lenta de uma evolução, mas para reencontrar as diferentes cenas onde eles desempenharam papeis distintos; e até definir o ponto de sua lacuna, o momento em que eles não aconteceram. (FOUCAULT, 2017, p.55)

Por meio de vestígios encontrados nas narrativas orais e escritas, realizou-se uma espécie de cartografia das sensibilidades dos estudantes sobre o 
espaço escolar habitado por eles. Esta cartografia não buscou apenas mapear ou descrever as experiências sensíveis, mas relacioná-las ao contexto histórico em que estavam inseridas, privilegiando o que era descontinuo.

Para Ricoeur (2007, p.58), “os lugares 'permanecem’ como inscrições, monumentos, potencialmente como documentos, enquanto lembranças transmitidas unicamente pela voz voam, como voam as palavras”. Há uma facilidade em lembrar dos espaços, pois, "o ato de habitar, [...] constitui, a esse respeito, a mais forte ligação humana entre a data e o lugar. Os lugares habitados são, por excelência, memoráveis. Por estar a lembrança tão ligada a eles, a memória declarativa se compraz em evoca-los e descrevê-los" (RICOEUR, 2007, p. 59).

Por isso, considerando a documentação consultada, percebemos que muito se escreveu sobre os prédios e espaços escolares, principalmente em datas comemorativas ou quando os estudantes concluem sua escolarização. O prédio estabelece uma espécie de vínculo perene que marca a identidade do estudante, na maioria dos casos. As expressões como Velho Casarão, Gigante da Duque, Velho Anchieta, cunhadas pelos estudantes, denotam essa relação do prédio com quem os frequentava. E essa relação se torna mais forte quando os discentes necessitam ressignificar esta identidade, principalmente em momentos de perda, seja pela saída da escola ou diante da iminência de destruição do edifício escolar.

Os vínculos que se estabelecem entre os estudantes e a materialidade escolar evocam uma profusão de discursos. Nestes, os espaços não são tomados apenas como cenário, mas também como responsáveis por incutir ações e valores, por exemplo, a prática da vigilância.

Sendo assim, as narrativas escritas ${ }^{7}$ e orais $^{8}$ foram articuladas em

\footnotetext{
7 Os escritos discentes revelam muito do espaço escolar e devem ser pensados como veículos importantes para a prática pedagógica. Para Almeida (2013, p.248) no que diz respeito aos periódicos, "traduzem aspectos significativos do cotidiano escolar e mostram indícios de saberes e de práticas escolares".
} 
quatro categorias de análise. Primeiramente, a questão entre o Antigo e o Novo. Ela emerge no campo discursivo quando há iminência de destruição do espaço escolar. Quando isso ocorre, os estudantes passam a olhar para o prédio antigo com saudosismo e projetam o que virá a ser o novo espaço. Por exemplo, nos Colégio Anchieta e Farroupilha, na década de 1960, houve a publicação de diversos artigos nos periódicos escolares que traziam esta dicotomia. Com isso, podem-se notar diferentes percepções sobre como os estudantes consideravam os edifícios antigos e novos.

Nesta categoria, inventariamos diversas narrativas que tratam dessa passagem de uma sede para outra. Sobre a construção do chamado "Novo Colégio Farroupilha" o aluno Mamfredo escreveu em sua redação: "sua imponência e grandiosidade não poderão apagar de minha memória aquela casa simples e antiga, em que aprendi a ler, em que passei horas felizes e amargas, e à qual devo a mais profunda gratidão: o antigo Farroupilha” (WAHMANN, 1956, p.2). Encontramos discursos similares em todas as instituições analisadas. No periódico estudantil do Colégio Anchieta, o ex-aluno descreve:

Finalmente, Anchieta, velho amigo, a ti nossas derradeiras palavras. Guardarás em tuas paredes, em tuas salas de aula, em tuas galerias, os nossos mais belos anos. Podes ficar certo de que, se algum dia caíres, se algum dia tiveres que morrer em benefício do progresso, levarás, impregnado em cada tijolo, em cada pedacinho de teu reboco, parte de nossa juventude. Nossa despedida é apenas aparente, pois em espírito estaremos sempre juntos e prontos a combater pelo mesmo ideal (SOUZA, 1961, p.9).

Em paralelo às representações sobre o Antigo e o Novo, emergiu o discurso da "escola como casa". Para diversos estudantes, o ambiente escolar assume como característica o fato de ser um local acolhedor, que se aproxima da ideia da casa dos pais. Durante o período da escolarização, passa-se muito

8 Diferente das pistas deixadas pelos discursos nos jornais escolares e nas fotografias, os depoimentos orais apresentam as marcas dos processos de ressignificação da memória, e de que forma os sujeitos internalizaram a questão do espaço e do prédio escolar. Com isso, se têm outras particularidades para a análise das questões sensíveis das memórias dos estudantes. 
tempo vivenciando a Arquitetura da escola e seu espaço funcional. Além do espaço habitável ser, por excelência, memorável, como diz Ricoeur (2007), pode este mesmo espaço produzir sensações de pertencimento? Como se constrói esta sensação de estar em meio ao lar? As narrativas orais e escritas evidenciam a recorrência de um discurso do prédio da escola como se fosse a casa do estudante.

Dito isso, trazemos um excerto de um escrito da estudante Mara Momaco, publicado no jornal "O Crisol", do Grêmio Estudantil das alunas do Colégio Americano,

Mais do que por recordações que me são infinitamente queridas, mais do que pela vida feliz de estudante que aqui passei, estarei sempre ligada ao Americano em todos os momentos da minha vida. É que no Americano cresci e me formei, assim como o vi crescer e formarem-se seus edifícios. Por tudo isto sinto que é muito difícil para mim olhá-lo pelo lado de fora e dizer - adeus (MOMACO, 1927, p.2).

A estudante sintetiza um momento particular na vida discente, o último ano do Curso Ginasial. Mara, ao registrar suas impressões acerca do último ano na escola, vincula sua história de vida à história do Colégio Americano, notadamente quando escreve, "é que no Americano cresci e me formei, assim como o vi crescer e formarem-se seus edifícios. Por tudo isto, sinto que é muito difícil para mim olhá-lo pelo lado de fora e dizer - adeus" (MOMACO,1930, p.2). A estudante, dentro de inúmeras possibilidades discursivas, optou por tratar sobre uma das coisas que mais a marcava na escola, a estrutura arquitetônica.

A autora atrela a construção dos espaços à sua própria formação na instituição, deixando claro que as memórias do Americano, são suas também. Sobre estas memórias do Colégio Americano, a ex-aluna Nelly, discorre, 
até a Independência. E logo adiante ficava o colégio. Era um prédio imponente, de classe.Tinha um jardineiro, o Seu Eduardo, que gostava muito da gente e cuidava de tudo. $\mathrm{O}$ jardim tinha um aquário com peixinhos dourados, orquídeas, tinha um chafariz bem grande, onde na base ficavam outros peixinhos dourados. E no centro do chafariz tinha uma planta chamada Escadinha do céu. Tinha um escorregador que ficava no pátio, nós procurávamos muito para brincar.Eu gostava muito do Colégio Americano. (Nelly, entrevista em 08/12/2014).

A imponência do prédio, as entradas da escola e o chafariz do jardim são elementos espaciais não levados pelo esquecimento. Na entrevista, Nelly lembra do jardim com um imenso carinho, e exemplifica dizendo que lá aconteciam as Festas da Primavera. As atividades lúdicas vividas naquele espaço foram lembradas facilmente pela estudante. Situações em que o aluno assume posicionamentos ativos são difíceis de serem esquecidas, principalmente porque escapam da normalidade, do que acontecia diariamente e por se tratar de um evento que envolvia a comunidade escolar. Da fachada do prédio, só recorda a imponência, do interior enfatiza os locais pelas quais tinha maior predileção.

No editorial de "O Crisol", de setembro de 1926, as estudantes fazem uma retrospectiva sobre o prédio do Americano na Av. Independência,

Com o maravilhoso impulso comprava-se em 1920 uma excellente propriedade na rua principal da capital riograndense.

O terreno é espaçoso, esplendidamente situado num ponto accessivel de toda parte da cidade. O edifício adquirido é um confortável palacete, que com algumas reformas bem se adaptou às necessidades do collegio para o anno de 1921.

Em 1922 inaugurava-se a construcção do novo edifício e a reforma geral do velho. Completada a obra em 1923, passou o primitivo Collegio a servir para dormitórios e os refeitórios e o novo prédio, Ipyranga a comportar as aulas, audictorium, etc. Em 1925 foi construído mais um edifício para o departamento de música. [...] Grande número de jovens brasileira vem avidamente procurar as luzes da instrucção neste estabelecimento. (CRISOL, 1926, set. n.4, p.2)

A partir do depoimento de Nelly, do excerto de Mara Momaco e do 
Editorial, conclui-se que o prédio faz parte do imaginário das alunas. Dos discursos analisados, não se localizaram representações que destoassem dessa visão idealizada e romantizada do prédio e de seu entorno. Sendo o prédio do Americano, um local "moderno", detentor das "luzes da instrução", esta perspectiva está de acordo com os ideais republicanos para a educação daquele período, no Rio Grande do Sul.

Em outra reportagem de "O Crisol", a aluna chamada de Apê tece outros comentários sobre o espaço do Americano. Ela se remete ao prédio do Americano como sendo lugar de uma família, ao comparar com suas janelas, aproximando a edificação à uma casa de família. Nesse aspecto, considera-se a materialidade como potencializadora de identidades, principalmente, para os estudantes que estão deixando a escola.

Esta noção do espaço como casa é enfatizada em um panfleto distribuido pela escola,

O colégio americano funciona em dois grandes e confortáveis edifícios, situados no mesmo terreno. O edifício onde ficam situados os dormitórios foi reformado e está em ótimas condições de oferecer conforto e comodidade as alunas internas. Possui sala de jantar com bem montada cozinha e dispensa. Os quartos de dormir são arejados e bem iluminados, os quartos de banho são fornecidos de água quente e fria. O edíficio de aulas é completamente novo, construido conforme as ultimas exigências de uma escola moderna. As salas de aula são grandes, bem arejadas e iluminadas. Possui carteiras capazes de se adaptarem ao tamanho da aluna. (AMERICANO, 1924, p.7)

Sobre isso, pode-se pensar que uma das intenções era tornar o espaço agradável para as estudantes, especialmente as que frequentavam o internato. Encontramos vários documentos que tratam o internato como um local que representava a "proteção da casa familiar" (Crisol, 1927).

Para contrapor os depoimentos, trazemos o excerto de "O Crisol"9 de outubro e novembro de 1927 , em que a estudante A. enfatiza a questão do

9 Sobre o periódico escolar das alunas do Colégio Americano: O Crisol, ver Almeida (2013). 
prédio do conservatório de música,

\begin{abstract}
Este edifício está situado no fundo do pateo. É interessante ouvirse tocar seis pianos ao mesmo tempo é um jazz-band infernal (grifos nossos). Finalmente temos o internato, muito alegre e que nos dá a impressão de uma casa habitada por uma grande família, sendo a mãe dedicada, nossa diretora. Os dormitorios são muito arejados e bem cuidados. A comida é de bom paladar e muito saudável. (A. $9^{\circ}$ ano. Crisol, 1927, P.2)
\end{abstract}

Ao mesmo tempo que uns discursos enfatizam a tranquilidade do ambiente, outros, como o excerto anterior, comentam sobre o barulho dos instrumentos do conservatório. Na sequência do texto, a autora volta a tratar dos demais espaços e a comparar o internato com uma casa de família, sendo a diretora, a "mãe espiritual" (ALMEIDA, 2013). A questão materna, neste caso, remete mais uma vez ao ambiente familiar e a questão do cuidado e do ensino às "filhas espirituais", que outrora era imputado às mães.

Durante a análise, ponderamos se esta sensação não era exclusiva do prédio da Av. Independência, por ser mais antigo e pela difusão dos discursos de pertencimento. Porém, a mesma se repete com a mudança do Colégio Americano para o Bairro Rio Branco.

Esta nova edificação possuía, o lema do escolanovista, John Dewey visível na fachada de entrada da instituição: "Educar é ensinar a viver". A partir disso, infere-se que essas ideais não só permeiam os espaços, mas fazem parte da filosofia da instituição. Além disso, a escolha pela frase de Dewey revela aproximações da instituição com ideais norte-americanos. Este também era o local em que as estudantes entravam na instituição, sendo assim a inscrição na parede estava em um local bem visível, justamente para não ser esquecida.

A influência dos ideais da Pedagogia Ativa, da filosofia das instituições, as diversas atividades extraclasse, a utilização do espaço fora da sala de aula, a manutenção da presença dos alunos no ambiente escolar fora do período de aulas, podem ser alguns dos fatores que incutiram nas estudantes este 
sentimento de pertencimento. Além disso, no Colégio Americano, pela observação das propagandas difundidas pela escola, constatou-se que o prédio do internato buscava mimetizar a casa familiar, talvez para que as estudantes melhor aproveitassem o período habitado na instituição. Esta visão idílica foi problematizada com a intenção de desnaturalizar este lugar que não é neutro e, a partir do que diz Foucault (1977), tem a intenção de docilizar o estudante.

Nesta perspectiva, regulação e punição caracterizam o espaço escolar, situação evidenciada em diversos depoimentos e escritos que explicitam esse caráter ordenatório. Entretanto, o mesmo ambiente que vigia e pune também permite práticas de recreação, assim essa foi outra questão que procurei investigar estas situações dicotômicas. Sobre isso, o ex-aluno Martin narra:

\footnotetext{
Assim, eu não amava a estrutura do colégio, o prédio em si não era uma coisa que me causava boa impressão. Eu achava meio sombrio, as cores escuras a arquitetura dele, provavelmente cinza escuro. Como ele era internamente, principalmente, as partes de madeira, forros. Não eram alegres. $E$ eu detestava ficar preso né, a minha alegria era o momento que saia né, que tinha que criar alguma coisa. Lá dentro tu tinhas que ficar quieto, prestar atenção, repetir. (Martin, entrevista em $12 / 12 / 2015)$
}

Na narrativa de Martin, percebe-se que a estrutura do colégio não lhe agradava. Durante a entrevista, essa lembrança foi recorrente, principalmente pela existência de uma maquete da casa que morou na infância. Para ele, esta moradia estava ligada à perspectiva da liberdade, por ser espaçosa e, inclusive, por ter uma casa na árvore. Ao contrário do colégio, que produzia nele uma sensação de aprisionamento.

Sobre essa entrevista, nota-se que as memórias de Martin denotam emoções não agradáveis vividas na década de 1950. Neste sentido, suas sensações representam o que foi dissonante nas narrativas sobre os prédios intitulados de "velhos", visto que a maioria dos entrevistados possuía memórias agradáveis sobre eles, sendo esta uma temática recorrente. 
A última categoria cartografada enfatiza a chamada "sensação de liberdade" trazida pelos estudantes. Essa sensibilidade é interessante de ser pensada, pois, com a institucionalização da escola, houve, conforme Varela e Uria (1992, p.230), a emergência de um "espaço fechado como dispositivo institucional"10. Este tinha a função de enclausurar e isolar os estudantes do "mundo e principalmente de seus prazeres", ligada diretamente pela referência aos conventos e às escolas de ordem religiosas, precursoras desta ordenação espacial.

Pensando nas memórias investigadas pela pesquisa e nas escolas do século $\mathrm{XX}$, percebe-se que esta função ainda permanece. A constituição de muitos espaços ainda possibilita e remete este sentido de aprisionamento e regulação dos estudantes. Considerando que o "espaço fechado não é em absoluto homogêneo" (VARELA;URIA,1992,p.230), outros sentidos podem ser atribuídos. O que significa que mesmo nestes locais havia uma flexibilização dos espaços com áreas que possibilitassem momentos de fuga deste aprisionamento, como jardins, pátios e outras áreas. Para Marcos, ex-aluno do Colégio Anchieta:

Naquela época, por causa do tamanho da escola os grupos não socializavam. Logo no início ali na frente não tinha nada, a gente ia caminhar na grama. A gente tinha aula de botânica ali no mato mesmo. E ao mesmo tempo tinha lugar pra matar aula, pra se esconder, uma série de outras coisas. Era tudo mais livre (Marcos, entrevista em 20/03/2016).

A nova localização da instituição possibilitou uma série de apropriações do espaço. A partir da narrativa de Marcos, pode-se inferir que o terreno medindo oito hectares possibilitou a construção de uma obra de grandes proporções, e, a partir disso, havia esta característica dispersiva, mas que, ao mesmo tempo, também facilitava a criação dos grupos de estudantes. Como ressaltou Marcos,

$10 \mathrm{O}$ estudo trata especificamente das escolas, porém também são considerados espaços de enclausuramento como: "albergues, casas prisões, casas da doutrina, casas de misericórdia, hospícios, seminários e hospitais” (VARELA;URIA, 1992, p. 230) no século XVII. 
O colégio sendo daquele tamanho, propiciava aos alunos terem um espaço para os seus grupos que se espalhavam. Tinha o grupo que ficava na Igreja, nos campos, na quadra. As quadras eram muito usadas nos recreios. Todo mundo jogava. Hoje ninguém joga, os recreios são todos separados, cada um em um horário. Os nossos eram todos juntos. [grifo meu] Tinha muitos espaços que propiciavam isso (Marcos, entrevista em 20/032016).

Além da questão estrutural, importa dizer que estes novos espaços contribuíram também para a prática pedagógica. Nas entrevistas citadas anteriores, há menção dos estudantes utilizando os banhados e a vegetação do entorno para as aulas de Biologia. Estas novas atividades possivelmente permitiam que o estudante tivesse uma postura mais ativa em sua escolarização. Isso também poderia facilitar para que houvesse essa sensação de liberdade visto que estas experiências não eram possíveis na localização anterior. Além disso, inferimos que, naquele momento, a escola se encontrava imbuída de ideais da Escola Nova que postulam o "aprender-fazendo" e a "escolalaboratório".

Este espaço provocava no estudante Marcos uma sensação de deslumbramento. Ao mesmo tempo, ele reitera a questão do enclausuramento da escola, através da palavra rigor. Isso tudo, concomitantemente com um pouco de liberdade por parte da instituição.

Inferimos que a percepção de um espaço na qual a liberdade predomina emerge nos momentos em que se rompe com a sala de aula. Especialmente, no contato com os pátios, ginásios, quadras e outras áreas da instituição que não fossem a sala de aula.

Através das memórias dos estudantes sobre os espaços de sua escolarização, analisou-se de que forma eles percebiam estas construções que segundo, Varela e Uria (1992, p. 5), procuravam "ocupar o tempo e imobilizar no espaço os estudantes". Esta sensação de liberdade rompe, ainda que parcialmente com o confinamento pretendido pelas instituições escolares. 


\section{CONCLUINDO}

Para finalizar, a partir das temáticas inventariadas: o antigo e o novo; a escola feito casa; espaços de regulação e punição e a sensação de liberdade, procurou-se investigar quais sensibilidades os prédios e espaços evocaram nos estudantes, quais usos os sujeitos deram para esta materialidade e de que forma estas lembranças foram ressignificadas.

Ao problematizar esses aspectos do espaço escolar, a partir das ferramentas teórico-metodológicas da história das sensibilidades, percebemos que,

\footnotetext{
Não vivemos em um espaço neutro e branco; não vivemos, não morremos e não amamos no retângulo de uma folha de papel. Vivemos, morremos e amamos em um espaço esquadrado, recortado, multicor, com zonas claras e sombras, diferenças de níveis, degraus, cavidades, protuberâncias, regiões duras e outras quebradiças, penetráveis, porosas (FOUCAULT, 2009, p.23-4).
}

Esse pequeno excerto faz parte de um dos chamados "Ditos e escritos" do filósofo francês. Nele, o autor faz uma espécie de reflexão acerca da complexidade de nossas existências. $\mathrm{O}$ autor reforça que "não vivemos em uma espécie de vazio" (Foucault, 2009, p. 24), mas sim em um espaço complexo permeado por histórias e memórias. E vem ao encontro do que diz o arquiteto Igor Guatteli, o "espaço é o lugar do hábito, de imprevistas habitabilidades, de habitações momentâneas [...] pois, como foi para os pós-estruturalistas, é o lugar do evento, do acontecimento, da indefinição e do imprevisível) Guatteli, 2012, p.15).

Com isso, nos amparamos no que diz Paul Ricoeur, justamente por considerar que o "habitar" uma determinada materialidade produz diversas memórias ricas em sensibilidades. Além disso, como podemos relacionar História da Arquitetura escolar e Sensibilidades? A título de resposta, podemos constatar que os espaços escolares não são isolados daqueles que os frequentam. 
Estes são projetados pelos arquitetos, porém quem define o uso são os sujeitos. O mesmo sujeito que vivencia o espaço é o mesmo que lembra. Logo, para a investigação, os espaços educativos só se tornaram lugares após serem vivenciados e utilizados pelos estudantes que rememoraram. Estas questões trazidas se identificam aos edifícios escolares analisados, pois, é a partir deste ato de habitar que o espaço é transformado em um lugar, e este evoca memórias.

Ao longo da pesquisa, foi necessário refletir sobre os sentidos do prédio escolar. Conclui-se que, além de abrigar as práticas educativas, tem como principal função a de ser ocupado pelos estudantes. Este ato de habitar é repleto de sensações de confinamento, clausura, imobilização dos sujeitos, por outro lado, há o sentido de esteio, um local que acolhe, protege e se torna uma referência para os estudantes, que pode extrapolar os anos de escolarização.

Por fim, percebemos indícios de como as sensibilidades dos estudantes foram construídas tomando o espaço como seu evocador e também como cenário. Esta visão mais aprofundada das sensações dos espaços escolares em Porto Alegre só foi possível, pois os estudantes reagem aos discursos e estímulos evocados pelos edifícios escolares, e com esse ato de experienciar o espaço, produzem sensações. A profusão dos discursos sensíveis sobre estas materialidades só confirma a importância que estes espaços adquirem na vida de quem os frequenta, corroborando com o que diz Michel de Certeau: "que todo o relato é um relato de viagem- uma prática de espaço” (p.200).

\section{REFERÊNCIAS}

ALBERTI, Verena. Histórias dentro da História. In: PINSKI, Carla Bassanezi (org.). Fontes Históricas. São Paulo: Contexto, 2005.

Manual de História Oral. Rio de Janeiro: FGV, 2013.

ALMEIDA. Dóris Bittencourt. O Crisol: periódico das alunas do Colégio Americano (Porto Alegre/RS, 1945-1964). Hist. Educ. (Online). Porto Alegre; 
v. 17 n. 40 Maio/ago. 2013 p. 267-290.

BASTOS, Maria Helena Camara; JACQUES, Alice Rigoni; ALMEIDA, Dóris Bittencourt Almeida. Do Deutscher Hilfsverein ao Colégio Farroupilha: entre memórias e histórias (1858-2008). Porto Alegre: Edipucrs, 2013.

BENCOSTTA, Marcus Levy. Apresentação do Dossiê - Arquitetura Escolar. Revista Linhas. Florianópolis, v. 12, n. 01, p. 03 - 04, jan. / jun. 2011 . História da Educação, Arquitetura e Espaço Escolar. São Paulo: Cortez, 2005.

- A escrita da Arquitetura Escolar na historiografia da educação brasileira (1999-2018). Revista Brasileira de História da Educação, UEM, Maringá, v.19, 2019.

BOTO, Carlota. A Liturgia Escolar na Idade Moderna. Campinas: Papirus Editora, 2017.

CERTEAU, Michel de. A escrita da história. Rio de Janeiro: ForenseUniversitária, 2007.

2008.

. A invenção do cotidiano. Artes de fazer. Petrópolis/RS: Vozes,

CHARTIER, Roger. A história cultural entre práticas e representações. Lisboa: Difel, 1987.

CHATELET, Anne-Marie. Ensaio de Historiografia I: a arquitetura das escolas no século XX. História da Educação, ASPHE/FaE/UFPel, Pelotas, n. 20, p. 7-38, set. 2006.

. Diálogos - entrevista com Anne-Marie Châtelet. Entrevistador:

Marcus Levy Bencostta. Revista Linhas, Florianópolis, v. 12, n. 01, p. 210-219. Jan./jun. 2011.

CORBIN, Alain. O prazer do historiador. Entrevistador: Laurent Vidal. Revista Brasileira de História, São Paulo, v.25, n. 49, p. 11-31, 2005.

CUNHA, Maria Teresa Santos. Acervos Escolares no Tempo Presente. Revista História da Educação, v. 18, n.47, 2015.

Nas Margens do Instituído: Memória e Educação. História da Educação (UFPel), Porto Alegre, v. 3, n.5, p. 39-46, 1999.

DÓREA, Célia Rosângela. A arquitetura escolar como objeto de pesquisa em 
História da Educação. Educar em Revista, Curitiba, Brasil, n.49, p. 161-181, jul. /set. 2013. Editora UFPR.

ERMEL, Tatiane de Freitas. O "gigante do alto da bronze": um estudo sobre o espaço e arquitetura escolar do Colégio Elementar Fernando Gomes em Porto Alegre/RS (1913 - 1930). 2011. 173 f. Dissertação. (Mestrado em Educação) - Programa de Pós-Graduação em Educação/PPGE, Pontifícia Universidade Católica do Rio Grande do Sul, Porto Alegre, 2011.

ESCOLANO BENITO, Agustin. A escola como cultura: experiência, memória e arqueologia. Campinas: Alinea, 2017.

ESCOLANO BENITO, Agustin. Arquitetura como programa. Espaço-escolar e currículo. IN: VIÑAO FRAGO, Antonio; ESCOLANO, Agustín. Currículo, Espaço e Subjetividade: a arquitetura como programa. Rio de Janeiro: DP\&A, 2001.

Emociones \& Educacion: La construcción histórica de la educación emocional. Madrid: vision libros, 2018.

FARGE, Arlette. O sabor do arquivo. São Paulo: Edusp, 2009.

. Lugares para a história. Belo Horizonte: Autêntica editora, 2015.

FARIA FILHO, Luciano Mendes de. Dos pardieiros aos palácios: forma e cultura escolar em Belo Horizonte (1906/1918). Uberlândia: Edufu, 2014.

FISCHER, Rosa Maria Bueno Fischer. Trabalhar com Foucault: arqueologia de uma paixão. Belho Horizonte: autêntica, 2012.

FOUCAULT, Michel. A ordem do discurso: aula inaugural no Collège de France, pronunciada em 2 de dezembro de 1970. São Paulo: Loyola, 1999.

. Microfísica do poder. São Paulo: Saraiva, 2017.

. Vigiar e punir: nascimento da prisão. Petrópolis,RJ: Vozes, 2014.

A arqueologia do saber. Rio de Janeiro: Forense Universitária, 2007.

Entrevista com Michel Foucault (1977). IN: . Genealogia da Ética, Subjetividade e Sexualidade. Ditos \& Escritos IX. Rio de Janeiro: Forense, 2014, p. 13-34.

O sujeito e o poder (1982). In: Genealogia da Ética, Subjetividade e Sexualidade. Ditos \& Escritos IX. Rio de Janeiro: 
Forense, 2014, p. 118-140.

. Nietzsche, a genealogia, a história (1971). In: Arqueologia das

Ciências e História dos Sistemas de Pensamento. Ditos \& Escritos II. Rio de Janeiro: Forense, 2008, p. 260-281.

GRIMALDI, Lucas Costa.; ALMEIDA, Dóris Bittencourt. “A TORRE AZUL”: memórias de espaços escolares pelas narrativas de estudantes e professores (1954-1996). Revista Educação em Questão, v. 56, n. 48, 17 jul. 2018.

GRIMALDI, Lucas Costa; ALMEIDA, Dóris Bittencourt. Memórias em palimpsesto: prédios e espaços escolares nas narrativas de estudantes em Porto Alegre/RS (1920-1980). Revista Cadernos de História da Educação, 2020. (No prelo)

GRUZINSKI, Serge. Por uma história das sensibilidades. In: PESAVENTO, Sandra Jatahy; LANGUE, Frédérique. (Orgs.). Sensibilidades na história: memórias singulares e identidades sociais. Porto Alegre: UFRGS, 2007.

GUATELLI, Igor. Arquitetura dos entre-lugares: sobre a importância do trabalho conceitual. São Paulo: Editora Senac, 2012.

JULIA, Dominique. A cultura escolar como objeto histórico. Revista Brasileira de História da Educação. $n^{\circ} 1$ jan./jun. 2001. P.9-43.

MARCOS. Entrevista concedida à Lucas Grimaldi. Porto Alegre, $07 \mathrm{de}$ abril de 2016. Entrevista.

MARTIN. Entrevista concedida à Lucas Grimaldi. Porto Alegre, 10 de dezembro de 2015. Entrevista.

Nelly. Entrevista concedida à Lucas Grimaldi. Porto Alegre, o9 de março de 2015. Entrevista.

NORA, Pierre. Entre Memória e História: a problemática dos lugares. Proj. História, São Paulo, (10), dez. 1993

NÓVOA, Antonio. Carta a um jovem historiador da educação.,Historia y Memoria de La Educación, 1 (2015): 23-58.

OLIVEIRA, Marcus Aurelio Taborda de. (Org.). Diálogos sobre a História da Educação dos sentidos e das sensibilidades. Curitiba: Edufpr, 2017.

. Educação dos sentidos e das sensibilidades: entre a moda acadêmica e a possibilidade de renovação do âmbito das pesquisas em história da educação. Hist. Educ. (Online) Porto Alegre v. 22 n. 55 maio/ago. 2018 p. 116-13 
PESAVENTO, Sandra Jatahy; LANGUE, Frédérique. (Orgs.). Sensibilidades na história: memórias singulares e identidades sociais. Porto Alegre: UFRGS, 2007.

PESAVENTO, Sandra Jatahy. História \& História Cultural. Belo Horizonte: Autêntica, 2005.

Cidades visíveis, cidades sensíveis, cidades imaginárias. Revista Brasileira de História, v. 27, n.53, jun. 2007.

PORTELLI, Alessandro. A História Oral como arte da escuta. São Paulo: Letra e voz, 2016.

RICOEUR, Paul. A memória, a história, o esquecimento. Campinas: Unicamp, 2007.

STEPHANOU, Maria; BASTOS, Maria Helena. História, Memória e História da Educação. In: STEPHANOU, Maria; BASTOS, Maria Helena. (Orgs.).

Histórias e Memórias da Educação no Brasil. Porto Alegre: Vozes, 2005.

VARELA, Julia. ALVAREZ-URIA, Fernando. A maquinaria escolar. Teoria \& Educação. Porto Alegre, n 6, 1992. p.225-246.

VIÑAO FRAGO, Antonio. Historia de la educación y historia cultural. Posibilidades, problemas, cuestiones. Revista Brasileira de Educação. Set/out/Nov/dez. 1995.

. Do espaço escolar e da escola como lugar: propostas e questões. In: VIÑAO FRAGO, Antonio; ESCOLANO, Agustín. Currículo, Espaço e Subjetividade: a arquitetura como programa. Rio de Janeiro: DP\&A, 1998.

VIÑAO FRAGO, Antonio; BENCOSTTA, Marcus Levy. Entre a multidisciplinariedade e a história: o espaço e a arquitetura escolares nas recentes historiografias educativas espanholas e brasileira. In: ARAUJO, Marta Maria de. (Org.). História(s) Comparada(s) da Educação. Brasília: Liber Livro, 2009.

VIÑAO FRAGO, Antonio; ESCOLANO, Agustín. Currículo, Espaço e Subjetividade: a arquitetura como programa. Rio de Janeiro: DP\&A, 1998.

VIÑAO FRAGO, Antonio. Historia de la educación y historia cultural. Posibilidades, problemas, cuestiones. Revista Brasileira de Educação. Set/out/Nov/dez. 1995. 
LUCAS COSTA GRIMALDI é doutorando em educação no Programa de PósGraduação em Educação da UFRGS.

E-mail: lucascgrimaldi@gmail.com

(D) http://orcid.org/0000-0003-4654-1032

DÓRIS BITTENCOURT ALMEIDA é professora de História da Educação da Faculdade de Educação e do Programa de Pós-graduação em Educação da Universidade Federal do Rio Grande do Sul (Ufrgs).

E-mail:Almeida.doris@gmail.com

(1) http://orcid.org/0000-0002-4817-0717

Recebido em: 20/10/2019

Aprovado em: 10/01/2020 